\title{
Critical Care Nursing
}

National Cancer Institute

\section{Source}

National Cancer Institute. Critical Care Nursing. NCI Thesaurus. Code C17602.

Critical care nursing is that specialty within nursing that deals specifically with human responses to life-threatening problems. A critical care nurse is a licensed professional nurse who is responsible for ensuring that all critically ill patients and their families receive optimal care. (AACN) 